\title{
EFFECTIVE MANAGEMENT OF ORGANIZATION AS A FACTOR OF ORGANISATIONAL CLIMATE
}

\author{
Neonila Partyko ${ }^{1}$ \\ Iryna Savka ${ }^{2}$
}

DOI: https://doi.org/10.30525/978-9934-588-15-0-125

Abstract. The article deals with the managing an organization as a factor of organizational climate. The main aim of the research was to diagnose the organizational climate in staff teams based on the analysis of its components and determination of its impact on managing an organization. The set of psychodiagnostic methods was used: the questionnaire "Organizational climate and efficiency of managing an organization", the test "Evaluation of the head effectiveness". To investigate the state of the organizational climate in the organization, we used the following indicators: relations with colleagues, attitude to work, professional development, authority of the head, satisfaction with working conditions, satisfaction with working hours, labour remuneration and the risk of losing a job. Such indicators were determined due to the understanding of the organizational climate as an indicator of group mood and the qualitative side of interpersonal relations in the group which integrates individual and group values, rules, processes, expectations, quality, and determines the psychological conditions that contribute to or impede effective joint activity to achieve the goals of the enterprise and the comprehensive development of the individual in the organization. The results of the research of mutual influence of the organizational climate of the Ukrainian state-owned enterprise and the processes of managing an organization have been presented in the article. Basically, the organizational climate reflects a person's perception of the organization to which he belongs. It is a set of unique characteristics and features that are perceived by the employees about their organizations which serves as a major force in

\footnotetext{
${ }^{1} \mathrm{PhD}$ (Psychology), Associate Professor,

Associate Professor at Department of Theoretical and Practical Psychology,

Lviv Polytechnic National University, Ukraine

${ }^{2} \mathrm{PhD}$ (Psychology),

Associate Professor at Department of Theoretical and Practical Psychology,

Lviv Polytechnic National University, Ukraine
} 
influencing their behaviour. Thus, organizational climate in a broad sense, can be understood as the social setting of the organization. The sample was drawn of 80 respondents from Pryvatbank Lviv State-Owned Enterprise. The questionnaire developed by A. Maier to evaluate the degree of optimality of the organizational climate, the test to evaluate the effectiveness of the head developed by S. Roshchin and indicators of organizational efficiency model developed by V. Sate were used for data collection. The linear correlation coefficient was used to check the hypothesis on the interrelation between climate indicators and its impact on management. The obtained results were presented using the correlation analysis and the method of correlation pleiades. The correlation pleiad obtained in the result of the research has showed a conspicuous tendency to the connection of the indicators of satisfaction with work schedule, level of salary and stability of the workplace with relations with colleagues, attitude to work, opportunity and desire for professional development as well as the authority of the direct supervisor and the quality of his decisions. Since the well-coordinated work of the team is gradually coming to the fore among the factors of competitive ability of the enterprise, it is relevant to conduct the study aimed at researching the features of the functioning of the organizational climate.

\section{Introduction}

The definition developed by Lawrence R. James and his colleagues makes a distinction between psychological and organizational climate. "Psychological climate is defined as the individual employee's perception of the psychological impact of the work environment on his or her own well-being (James \& James, 1989) [9]. When employees in a particular work unit agree on their perceptions of the impact of their work environment, their shared perceptions can be aggregated to describe their organizational climate (Jones \& James, 1979; Joyce \& Slocum, 1984)" [9].

Employees' collective appraisal of the organizational work environment takes into account many dimensions of the situation as well as the psychological impact of the environment. For instance, job-specific properties such as role clarity, workload and other aspects unique to a person's specific job have a psychological impact that can be agreed upon by members of the organization. Work group or team cooperation and effectiveness as well as leadership and organizational support are other dimensions of shared expe- 
rience that factor into organizational climate. Surveys are the most common way of quantifying organizational climate. Aspects of climate that influence performance of specific sets of behaviors and outcomes can be measured, such as the climate for safety and the climate for innovation.

Organizational climate and organizational culture are distinct concepts. Climate and culture are both important aspects of the overall context, environment or situation. Organizational culture tends to be shared by all or most members of some social group, is something that older members usually try to pass on to younger members, and shapes behavior, structures, and perceptions of the world. Cultures are often studied and understood at a national level, such as the American or French culture. Culture includes deeply held values, beliefs and assumptions, symbols, heroes, and rituals. Culture can be examined at an organizational level as well. The main distinction between organizational and national culture is that people can choose to join a place of work, but are usually born into a national culture.

Organizational climate, on the other hand, is often defined as the recurring patterns of behavior, attitudes and feelings that characterize life in the organization [9], while an organization culture tends to be deep and stable. Although culture and climate are related, climate often proves easier to assess and change.

According to Bowditch and Buono, organizational culture is connected with the nature of beliefs and expectations about organizational life, while climate is an indicator of whether these beliefs and expectations are being fulfilled. Climate of an organization is somewhat like the personality of a person. Just as every individual has a personality that makes him unique and different from other persons. Each organization has an organizational climate that clearly distinguishes it from other organizations.

Before understanding the meaning of organizational climate, we must first understand the concept of climate. Climate in natural sense is referred to as the average course or condition of the weather at a place over a period of years as exhibited by temperature, wind, velocity and precipitation. However, it is quite difficult to define organizational climate incorporating the characteristics of natural climate. This is so because the most frustrating feature of an attempt to deal with situational variables in a model of management performance is the enormous complexity of the management itself. People have defined organisational climate on the basis of its potential properties. A few important definitions are as given below. 
According to Forehand and Gilmer, climate consists of a set of characteristics that describe an organisation, distinguish it from other organisations are relatively enduring over time and influence the behaviour of people in it.

According to Campbell, organisational climate can be defined as a set of attributes specific to a particular organization that may be induced from the way that organization deals with its members and its environment. For the individual members within the organization, climate takes the form of a set of attitudes and experiences which describe the organization in terms of both static characteristics (such as degree of autonomy) and behaviour outcome and outcome contingencies.

Thus, organizational climate is a relatively enduring quality of the internal environment that is experienced by its members, influences their behaviour and can be described in terms of the value of a particular set of characteristics of the organization. It may be possible to have as many climates as there are people in the organization when considered collectively, the actions of the individuals become more meaningful for viewing the total impact upon the climate and determining the stability of the work environment. The climate should be viewed from a total system perspective. While there may be differences in climates within departments these will be integrated to a certain extent to denote overall organizational climate.

At an individual level of analysis the concept is called individual psychological climate. These individual perceptions are often aggregated or collected for analysis and understanding at the team or group level, or the divisional, functional, or overall organizational level.

Ravasi and Schultz (2006) characterise organizational culture as a set of shared assumptions that guide behaviors [9]. It is also the pattern of such collective behaviors and assumptions that are taught to new organizational members as a way of perceiving and, even thinking and feeling. Thus organizational culture affects the way people and groups interact with each other, with clients, and with stakeholders. In addition, organizational culture may affect how much employees identify with an organization.

In a corporation, a stakeholder is a member of "groups without whose support the organization would cease to exist" [10, p. 6], as defined in the first usage of the word in a 1963 internal memorandum at the Stanford Research Institute. The theory was later developed and championed by R. Edward 
Freeman in the 1980s. Since then it has gained wide acceptance in business practice and in theorizing relating to strategic management, corporate governance, business purpose and corporate social responsibility (CSR). The definition of corporate responsibilities through a classification of stakeholders to consider has been criticised as creating a false dichotomy between the "shareholder model" and the "stakeholders model" [9] or a false analogy of the obligations towards shareholders and other interested parties [11].

Any action taken by any organization or any group might affect those people who are linked with them in the private sector. For examples these are parents, children, customers, owners, employees, associates, partners, contractors, and suppliers, people that are related or located nearby. Primary stakeholders are usually internal stakeholders, are those that engage in economic transactions with the business (for example stockholders, customers, suppliers, creditors, and employees). Secondary stakeholders are usually external stakeholders, are those who - although they do not engage in direct economic exchange with the business - are affected by or can affect its actions (for example the general public, communities, activist groups, business support groups, and the media). Excluded stakeholders are those such as children or the disinterested public, originally as they had no economic impact on business. Now as the concept takes an anthropocentric perspective, while some groups like the general public may be recognized as stakeholders others remain excluded. Such a perspective does not give plants, animals or even geology a voice as stakeholders, but only an instrumental value in relation to human groups or individuals.

A narrow mapping of a company's stakeholders might identify the following stakeholders: employees, communities, shareholders, creditors, investors, government, customers, owners, financiers, managers. A broader mapping of a company's stakeholders may also include: suppliers, distributors, labor unions, government regulatory agencies, government legislative bodies, government tax-collecting agencies, industry trade groups, professional associations, NGOs and other advocacy groups, prospective employees, prospective customers, local communities, national communities, public at large (global community), competitors, schools, future generations, analysts and media, research centers.

It can be argued that the view on organizational culture as a significant factor of management is still not popular in our country. However, on the 
one hand, participation of authors in the implementation of psychological training of civil servants, teachers, social workers, employees of employment centers for the professional activity and, on the other hand, the preparation of private companies employees for management activity at business training courses showed the differences in the organizational cultures of private and state-owned enterprises. It can be said that the organizational culture of a private enterprise is result-oriented, and the essence of the organizational climate of a state-owned enterprise is focused on preserving the process more than on achieving the result. To check whether our observation is true, the idea came about an empirical research of the interaction of the organizational climate of the state-owned enterprise and the efficiency of managing an organization.

\section{Literature review}

The phenomena of organizational culture and national psychological climate are in the field of view of researchers for decades, however, this research is relevant up to day because these phenomena manifest themselves in different ways in diverse social and cultural communities.

Schein (1992), Deal and Kennedy (2000), and Kotter (1992) advanced the idea that organizations often have very differing cultures as well as subcultures. Although a company may have its "own unique culture," in larger organizations there are sometimes co-existing or conflicting subcultures because each subculture is linked to a different management team.

Flamholtz and Randle (2011) suggest that one can view organizational culture as "corporate personality". They define it as it consisting of the values, beliefs, and norms which influence the behavior of people as members of an organization.

Robbins Stephen P. and Coulter M. describe organizational culture as the employees' shared values, beliefs or perception of the organization or organizational unit. In view of the fact that organizational culture reflects the values, beliefs and behaviour used by the employees of an organization to give meaning to the situations they are faced with, it can affect the attitude and behaviour of the staff.

There are two difficulties in defining organization climate: how to define climate, and how to measure it effectively on different levels of analysis. Furthermore, there are several approaches to the concept of climate. Two 
in particular have received substantial patronage: the cognitive schema approach and the shared perception approach.

The cognitive schema approach regards the concept of climate as an individual perception and cognitive representation of the work environment. From this perspective climate assessments should be conducted at an individual level.

The shared perception approach emphasizes the importance of shared perceptions as underpinning the notion of climate. Organizational climate has also been defined as "the shared perception of the way things are around here". There is great deal of overlap in the two approaches.

Cognitive schema approach. Cognitive representations of social objects are referred to as schemas. These schemas are a mental structure that represents some aspect of the world. They are organized in memory in an associative network. In these associative networks, similar schemas are clustered together. When a particular schema is activated related schemas may be activated as well. Schema activation may also increase the accessibility of related schemas in the associative network. When a schema is more accessible this means it can more quickly be activated and used in a particular situation. When related schemas are activated, inferences beyond the information given in a particular social situation may influence thinking and social behavior, regardless of whether those inferences are accurate or not. Lastly, when a schema is activated a person may or may not be aware of it.

Two processes that increase the accessibility of schemas are salience and priming. Salience is the degree to which a particular social object stands out relative to other social objects in a situation. The higher the salience of an object the more likely that schemas for that object will be made accessible. For example, if there is one female in a group of seven males, female gender schemas may be more accessible and influence the group's thinking and behavior toward the female group member. Priming refers to any experiences immediately prior to a situation that caused a schema to be more accessible.

Shared perception approach. Some researchers have pursued the shared perception model of organizational climate. Their model identifies the variables which moderate an organisation's ability to mobilise its workforce in order to achieve business goals and maximise performance.

One of the major users of this model are departments of the Queensland State Government Australia. These departments use this model of climate 
to survey staff in order to identify and measure those aspects of a workplace which impact on: stress, morale, quality of work life, wellbeing, employee engagement, absenteeism/presenteeism, turnover and performance.

While an organization and its leaders cannot remove every stressor in the daily life of its employees, organizational climate studies have identified a number of behaviours of leaders which have a significant impact on stress and morale. For instance, one Queensland state government employer, Queensland Transport, has found that increasing managers' awareness of these behaviours has improved quality of work life employees and the ability of QT's to deliver its organizational goals.

Theories of cognitive and neuropsychology and emotional intelligence provide additional scientific rationale for why leaders should improve stress and morale in the workplace to achieve maximum performance. Climate surveys can provide concrete evidence of how this works in action.

Organizational climate surveying enables the impact of human resource (HR) strategies to be evaluated to create HR return on investment (HRROI) calculations. This data has been found to be highly effective in changing the perspective of people-based initiatives as being an "investment" rather than a "cost" and transforming HR into a "mission-critical strategic partner" from its perception of "personnel administration".

A number of studies by Dr Dennis Rose and colleagues between 2001-2004 have found a very strong link between organizational climate and employee reactions such as stress levels, absenteeism and commitment and participation.

A study has found that Hart, Griffin et al.'s (1996) organizational climate model accounts for at least $16.0 \%$ single-day sick leave and $10.0 \%$ separation rates in one organization. Other studies support the links between organizational climate and many other factors such as employee retention, job satisfaction, well-being, and readiness for creativity, innovation and change.

Hunter, Bedell and Mumford have reviewed numerous approaches to climate assessment for creativity. They found that those climate studies that were based on well-developed, standardized instruments produced far higher effect sizes than did studies that were based on locally developed measures.

The organizational climate can affect the human behaviour in the organization through an impact on their performance, satisfaction and attitudes. There are four mechanisms by which climate affects the behaviour of the employees. 


\section{Constraint System.}

Organizational climate can operate as a constraint system in both the positive and negative sense. This can be done by providing information to the employees about what kind of behaviour will be rewarded, punished or ignored. Thus, behaviour can be influenced by varying degrees of rewards and punishments. Such a constraint system would influence the behaviour of those people who are most interested in those specific values which are assigned to different behavioural outcomes.

2. Evaluation of Self and Others.

Organizational variables may affect behaviour through evaluation of self and others. In this evaluation process both the physiological and psychological variables will be associated. Such evaluation will affect the human behaviour.

3. By Acting as Stimuli.

Organizational factors can influence human behaviour by acting as stimuli. As stimuli they influence individual's arousal level, which is a motivational variable directing human behaviour. The level of arousal will directly affect the level of activation and hence performance.

4. By Helping the Individual to Form a Perception.

Organizational factors influence the behaviour by helping the individual in forming a perception of the organization. The perception then influences behaviour. Thus, good organizational climate is instrumental to higher employee satisfaction, better human relations and higher productivity, the role of climate can be explained with the help of the following figure.

The factors indicated in the figure represent major determinants of climate in an organization and as such represent important areas of management concern. If employees satisfaction and job performance are to be improved, the management must modify these factors so that the employees view climate as favourable to them. Various research studies also confirm the positive relationship between organizational climate and employee performance.

Frederiksen on the basis of laboratory studies involving 260 middle level managers concludes that different organizational climate has different impact on human performance. He summarizes that the amount of administrative work in the stimulated job is more predictable in a climate that encourages innovation, than in one that encourages standard procedures and 


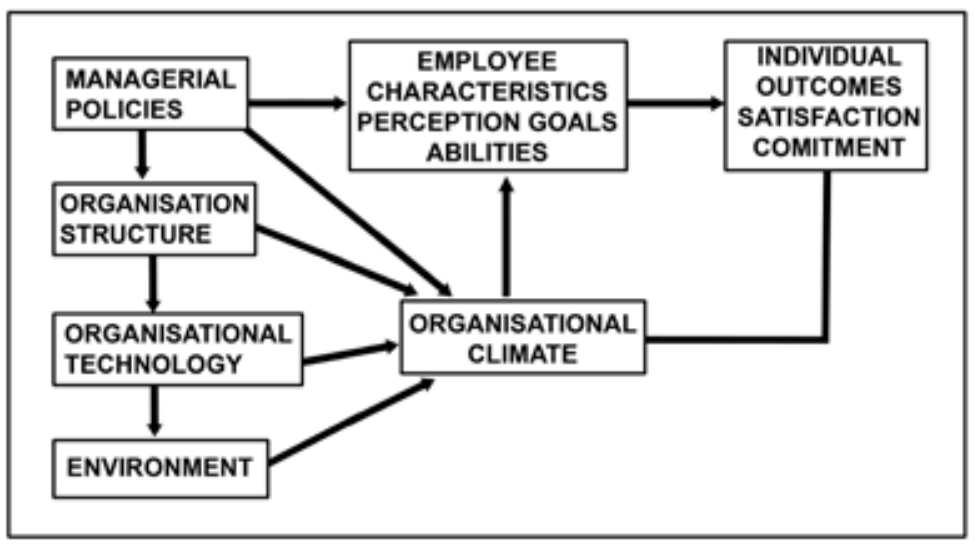

Figure 1. Organisational climate and effectiveness

that in an innovative climate, greater productivity can be expected of people with skills and attitudes that are associated with independence of thought and action and the ability to be productive in free unstructured situations.

This study suggests that the performance was more predictable for subjects who worked in a consistent climate than those who had to work in an inconsistent environmental climate. Inconsistent climate was having indirect impact on productivity. Another laboratory study shows that significant differences were found in performance and satisfaction of people in varying organizational climates.

According to Y.L. Neymer, the organizational climate reflects the internal state of any community, its complex ability to achieve the goals set. The author understands the inner state as the formation which unites the level of identification of the enterprise's staff with the society, values and norms of group behaviour, collective expectations and attitude of employees to management team [5].

The organizational climate is the state of group mood and the qualitative side of interpersonal relations in the group which integrates individual and group values, rules, processes, expectations of quality and determines the psychological conditions contributing or impeding effective joint activity to achieve the goals of the enterprise and the comprehensive development of the individual at the organization [4]. Later, the other researchers, 
Harris and Ogbonna also came to a conclusion that organizational culture affected community members not so much through bureaucratic procedures as through regulatory control because it includes system of rules and guidelines, both formal and informal, as well as a number of rituals and traditions, behavioural models of employees working within this organizational structure [10]. The specific ways of influencing the organizational climate onemployees as members of a particular community also include the impact on their attitudes to work, their sense of duty and responsibility to their colleagues and to the entire organization [12] as well as mutual dependence and care, altruism and positive paradigms [2, p. 15].

In the previous empirical research of the interrelation between organizational climate and management at the private enterprise was showen the strong interrelation between the indicators of organizational climate and managing an organization [4]. However, in the investigated group of private enterprise in the city of Lviv they found that relations with colleagues correlated with cooperation, authority of the head, communication, loyalty of the organization and sharing the values. Such an interrelation can be explained by the fact that the better the relations with colleagues, their perception of each other and themselves as part of the whole, the more effectively employees interact with each other regarding solving work issues [4]. Positive relations with colleagues also enable the head to more effectively perform other managerial functions, namely, control aimed at providing timely assistance to employees in order to achieve a managerial goals. It can be assumed that this phenomenon is caused by the increased availability of the private enterprise personnel for managerial influences, its integrity [4].

\section{Survey methodology}

The main aim of the research was to diagnose the organizational climate in staff teams based on the analysis of its components and determination of its impact on managing an organization. The set of psychodiagnostic methods was used: test "Evaluation of the head's effectiveness" and questionnaire "Organizational climate and efficiency of managing an organization".

To investigate the state of the organizational climate in the organization, we used the following indicators: relations with colleagues, attitude to work, professional development, authority of the head, satisfaction with working conditions, satisfaction with working hours, labour remuneration 
and the risk of losing a job. Such indicators were determined due to the understanding of the organizational climate as an indicator of group mood and the qualitative side of interpersonal relations in the group which integrates individual and group values, rules, processes, expectations, quality, and determines the psychological conditions that contribute to or impede effective joint activity to achieve the goals of the enterprise and the comprehensive development of the individual in the organization. The results are processed by calculating the points which are accrued according to the key and deducting its average value for each scale. The questionnaire used a three-dimensional scale. The obtained indication identified the presence of a low, average or high level by one or another indicator.

The questionnaire developed by A. Maier is the bases for the research and it gives the opportunity to quantitatively express the degree of optimality of the organizational climate, as well as identify the components of interpersonal relations that affect the formation of the organizational climate. The objective characteristics of labor are also measured, as well as the subjective perception of the situation. The next part of the questionnaire was aimed at measuring the impact of the organizational climate on managing an organization which is based on V. Sathe Organizational Efficiency Model [14]. According to this model, the following indicators were identified to determine the impact of the organizational climate on managing an organization: cooperation; decision-making; supervisor's control; organizing, management and supervision; communication; loyalty of the organization; values of the organization. Also, to investigate the efficiency of managing an organization, we used a test to evaluate the efficiency of the head which contains 30 factors that characterise strategic thinking, management skills, appetite for risk and innovation, the ability to create a positive psychological climate in the staff team and to motivate their employees for the best implementation of common tasks and other factors that are evaluated on a seven-point scale and indicate the level of management skills $[1 ; 6]$.

\section{Findings}

The linear correlation coefficient was used to check the hypothesis about the existence of interrelation between the organizational climate indicators and its impact on management. The calculation of Student's t-criterion was carried out using the SPSS 15 Statistical Package. The relations with col- 
leagues are correlated with the cooperation $(\mathrm{r}=0.54 ; \mathrm{p} \leq 0.01)$, management control $(\mathrm{r}=0.4 ; \mathrm{p} \leq 0.01)$, organizing, management and supervision $(\mathrm{r}=0.4$; $\mathrm{p} \leq 0.01)$ and decision-making of the head $(\mathrm{r}=0.42 ; \mathrm{p} \leq 0.01)$ with $\mathrm{n}=60$. It can be observed the tendency toward interrelation of the relations with colleagues and professional development $(\mathrm{r}=0.31 ; \mathrm{p} \leq 0.05)$, authority of the head $(\mathrm{r}=0.33$; $\mathrm{p} \leq 0.05)$, loyalty of the organisation $(\mathrm{r}=0.31 ; \mathrm{p} \leq 0.05)$ and labour renumeration $(\mathrm{r}=0.34 ; \mathrm{p} \leq 0.05)$. We understand the tendency toward interrelation of the relations with colleagues and professional growth, which can be observed only in this sample of the investigation, as the fact that the better relations in the staff team the greater opportunity and desire for the professional growth. Perhaps, the staff team acts as a kind of stimulus for a person to personal development and growth. In the above results at the private enterprise, we also identified interrelation between the cooperation and attitude to work $(\mathrm{r}=0.48 ; \mathrm{p} \leq 0.01)$, supervisor's control( $\mathrm{r}=0.52 ; \mathrm{p} \leq 0.01)$, authority of the head $(\mathrm{r}=0.45 ; \mathrm{p} \leq 0.01)$, decision-making $(\mathrm{r}=0.41 ; \mathrm{p} \leq 0.01)$, organising, management and supervision $(\mathrm{r}=0.45 ; \mathrm{p} \leq 0.01)$, loyalty of the organisation $(\mathrm{r}=0.5 ; \mathrm{p} \leq 0.01)$, value adoption $(\mathrm{r}=0.61 ; \mathrm{p} \leq 0.01)$ and labour renumeration $(\mathrm{r}=0.42 ; \mathrm{p} \leq 001)$. We understand the interrelation of the cooperation with labour renumeration as the fact that the better cooperation in the staff team, the more employees are satisfied with labour renumeration. It can be assumed that the existence of clear interaction between the main and auxiliary employees contributes to the achievement of the highest result in the work and affects the amount of remuneration or the availability of bonuses.

The attitude to work is related to the supervisor's control( $\mathrm{r}=0.48$; $\mathrm{p} \leq 0.01)$, professional development $(\mathrm{r}=0.48 ; \mathrm{p} \leq 0.01)$, decision-making, loyalty of the organization $(\mathrm{r}=0.48 ; \mathrm{p} \leq 0.01)$, value adoption $(\mathrm{r}=0.48 ; \mathrm{p} \leq 0.01)$ and labour renumeration $(\mathrm{r}=0.48 ; \mathrm{p} \leq 0.01)$. There is probable connection between positive perceptions of work and the authority of the head $(\mathrm{r}=0.39$; $\mathrm{p} \leq 0.05)$. Also, it is observed the tendency to the interrelation between the attitude to work and labour renumeration $(\mathrm{r}=0.39 ; \mathrm{p} \leq 0.05)$. Perhaps, the better employees evaluate the content of their work, the more they are satisfied with its renumeration. In the above case, it is not about absolute satisfaction with the amount of a salary. Most likely, when an employee is satisfied with the content of his work, he has the opportunity to realize himself and it positively affectsthe evaluation of labour renumeration system. Assessing the indicator of managing an organization and management control, we can 
see the relation with such indicators of the psychological climate as professional development $(\mathrm{r}=0.51 ; \mathrm{p} \leq 0.01)$, authority of the head $(\mathrm{r}=0.41 ; \mathrm{p} \leq 0.01)$ and labour renumeration $(\mathrm{r}=0.57 ; \mathrm{p} \leq 0.01)$.

The last link between labour renumeration and supervisor's control is interpreted as the fact that the more effectivethe manager implements the control function, the more employees are satisfied with labour renumeration which may be due to the increase of economic indicators and as a result the possible material incentives for workers.

Also the supervisor controlis related to organizing, management and supervision $(\mathrm{r}=0.44 ; \mathrm{p} \leq 0.01)$, loyalty of the organization $(\mathrm{r}=0.59 ; \mathrm{p} \leq 0.01)$ and value adoption $(r=0.66 ; p \leq 0.01)$. It is probable that there is a tendencyto the relation of supervisor's control with decision-making $(r=0.39 ; p \leq 0.05)$ and labour conditions $(\mathrm{r}=0.36 ; \mathrm{p} \leq 0.05)$.

Unlike the above results of the correlation analysis at the private enterprise, according to the indicators of supervisor's controlwith communication and the authority of the head with communication at the state-owned enterprise, such a connection wasn't revealed. The employees tend to evaluate positively their professional development at the state-owned enterprise in the case of effective manager decisions $(r=0.49 ; p \leq 0.01)$, manifestations of the organization loyalty to the employees $(\mathrm{r}=0.42 ; \mathrm{p} \leq 0.01)$ andsatisfaction with labour renumeration $(\mathrm{r}=0.47 ; \mathrm{p} \leq 0.01)$. That is with increasing wages, opportunities, desires and satisfaction with professional development are growing. There is a tendency to the connection between the professional development indicators and the authority of the head $(\mathrm{r}=0.35 ; \mathrm{p} \leq 0.05)$, organizing, management and supervision $(\mathrm{r}=0.32 ; \mathrm{p} \leq 0.05)$ and value adoption. There is the connection of satisfaction with one's head, that is the presence of authority, with other indicators of the efficiency of managing an organization, namely, decision-making $(r=0.74 ; p \leq 0.01)$, loyalty of the organisation $(r=0.46 ; p \leq 0.01)$, organising, management and supervision $(\mathrm{p}=0.51 ; \mathrm{p} \leq 0.01)$ and value adoption $(r=0.42 ; p \leq 0.01)$ and labour renumeration $(r=0.46 ; p \leq 0.01)$.

Interestingly, there is a precondition for satisfaction with the labour renumeration with the presence of authority of the head. It is possible that employees tend to correlate labour renumeration not only with their own material well-being, but also with the fact of its corresponding to the spentefforts and fair distribution that depends on the decisions of management team and its authority. 
Decision-making is more effective provided the organizing, management and supervision $(\mathrm{r}=0.71 ; \mathrm{p} \leq 0.01)$, communication $(\mathrm{r}=0.48 ; \mathrm{p} \leq 0.01)$ and loyalty of the organization are effective. There is a tendency to the relation of decision-making andvalue adoption $(\mathrm{r}=0.35 ; \mathrm{p} \leq 0,05)$. So, the employees accept organizational values when the manager's decisions are effective and positively accepted by the employees. The effectiveness of the organisation, management and supervision is determined by the indicators of the high level of communication $(r=0.58 ; \mathrm{p} \leq 0.01)$, organisation's loyalty $(\mathrm{r}=0.69 ; \mathrm{p} \leq 0.01)$, acceptance of the organization values $(\mathrm{r}=0.43 ; \mathrm{p} \leq 0.01)$. It is probable the relation of organisational efficiency, management, supervision with satisfaction with labour renumeration $(\mathrm{r}=0.38 ; \mathrm{p} \leq 0.05)$. There is the connection between communication and loyalty $(\mathrm{r}=0.43 ; \mathrm{p} \leq 0.01)$ and acceptance of values $(r=0.49 ; \mathrm{p} \leq 0.01)$. At the same time, unlike the private enterprise at the state one the relation of communication with labour renumeration and working conditions was not revealed. There is a tendency to the relation of loyalty of the organisation with acceptance of values $(r=0.31$; $\mathrm{p} \leq 0.05)$ and satisfaction with working conditions $(\mathrm{r}=0.3 ; \mathrm{p} \leq 0.05)$. There is a closer relation between loyalty and satisfaction with labour renumeration $(\mathrm{r}=0.41 ; \mathrm{p} \leq 0.01)$. Also, the correlation analysis revealed the tendency to the relation between labour remuneration and acceptance of the organization values $(\mathrm{r}=0.39 ; \mathrm{p} \leq 0.05)$ and working schedule $(\mathrm{r}=0.32 ; \mathrm{p} \leq 0.05)$ as well as the relation between labour renumeration and satisfaction with working conditions $(r=0.41 ; p \leq 0.01)$. The tendency to the acceptance of values and satisfaction with labour renumeration can be explained by the fact that the more employees identify themselves with the enterprise, the more they are inclined to accept a certain amount of salary for them. Also, satisfaction with labour renumeration is affected by satisfaction with work schedule. There is the causality of labour satisfaction not only with the ammount of salaries, but also a variety of other factors, among which there are satisfaction with the work schedule, working conditions, acceptance of values, loyalty of the organization, decision-making of the head, organising and management, professional development, attitude to work, relations with colleagues, cooperation and authority of the head. One can assume that the evaluation of labour renumeration is a very subjective and variable indicator.

Thus, we observe the interrelation of the psychological climate variable of "relations with colleagues" and the other management factors, namely, 
management team supervision $(\mathrm{r}=0.73 ; \mathrm{p} \leq 0.01)$, communication $(\mathrm{r}=0.73$; $\mathrm{p} \leq 0.01)$ and also the tendency to the connection with cooperation $(\mathrm{r}=0.68$; $\mathrm{p} \leq 0.05)$, attitude to work $(\mathrm{r}=0.58 ; \mathrm{p} \leq 0.05)$, professional development $(\mathrm{r}=0.67 ; \mathrm{p} \leq 0.05)$, authority of the head $(\mathrm{r}=0.58 ; \mathrm{p} \leq 0.05)$, decision-making $(\mathrm{r}=0.68 ; \mathrm{p} \leq 0.05)$, organising, management and supervision $(\mathrm{r}=0.64 ; \mathrm{p} \leq 0.05)$ and loyalty of the organization $(\mathrm{r}=0.54 ; \mathrm{p} \leq 0.05)$. It is interesting interrelation of colleagues with job stability $(\mathrm{r}=0.4 ; \mathrm{p} \leq 0.05)$. So, the more positive employees evaluate their collaborators, the less they evaluate the risk of losing their jobs. The cooperation is related to the attitude to work $(r=0.54$; $\mathrm{p} \leq 0.05$ ) and interacts conversely with the effectiveness of the head management $(r=0.4 ; p \leq 0.05)$. From our point of view, such a contradictory tendency can be understood as the fact that the less effective the management, the greater the tendency of heads to combine their efforts to ensure that the performance of the organization is not suffered. One can assume that if the level of the cooperation of employees is high the management team does not need to use all management powers and potential or the opportunities of management impact are reduced [3].

There is a tendency to the inverse relationship of decision-making and working conditions $(\mathrm{r}=-0.49 ; \mathrm{p} \leq 0.05)$. So, the more inefficient decisions takes the head, the less the employees happy with these decisions that can be expressed in their dissatisfaction with working conditions. The attitude to work is related to professional development $(\mathrm{r}=0,88 ; \mathrm{p} \leq 0,01)$, organizing, management and supervision $(\mathrm{r}=0.75 ; \mathrm{p} \leq 0.01)$ and communication $(\mathrm{r}=0.71$; $\mathrm{p} \leq 0.01)$. There is a tendency to the interrelation of work and authority of the head $(\mathrm{r}=0.64 ; \mathrm{p} \leq 0.05)$, decision-making $(\mathrm{r}=0.59 ; \mathrm{p} \leq 0.05)$, loyalty of the organization $(r=0,46 ; p \leq 0,05)$, labour renumeration $(r=0,46 ; p \leq 0,05)$ and job stability $(\mathrm{r}=0,61 ; \mathrm{p} \leq 0,05)$.

There is probable connection of the supervisior's control with variables of climate and management, namely, professional development $(\mathrm{r}=0.45$; $\mathrm{p} \leq 0.05)$, authority of the head $(\mathrm{r}=0.41 ; \mathrm{p} \leq 0.05)$, decision-making $(\mathrm{r}=0.45$; $\mathrm{p} \leq 0.05)$, communication $(\mathrm{r}=52 ; \mathrm{p} \leq 0.05)$ and loyalty of the organization $(\mathrm{r}=0.55 ; \mathrm{p} \leq 0.05)$. Professional growth is related with the authority of the head $(r=0.72 ; p \leq 0.01)$, decision-making $(r=0.72 ; p \leq 0.01)$, organizing, management and supervision $(\mathrm{r}=0.75 ; \mathrm{p} \leq 0.01)$ and communication $(\mathrm{r}=0.77$; $\mathrm{p} \leq 0.01$ ). One can observe the tendency to the interrelation of satisfaction with professional growth and loyalty of the organization $(r=0,69 ; p \leq 0,05)$, 
satisfaction with work schedule $(r=0,53 ; p \leq 0,05)$, labour $(r=0.65 ; p \leq 0.05)$ and the risk of losing a job $(\mathrm{r}=0.62 ; \mathrm{p} \leq 0.05)$. The authority of the head correlates with decision-making $(\mathrm{r}=0.84 ; \mathrm{p} \leq 0.01)$, organising, management and supervision $(\mathrm{r}=0.84 ; \mathrm{p} \leq 0.01)$ and communication $(\mathrm{r}=0.77 ; \mathrm{p} \leq 0.01)$. There is the tendency to the interrelation of the indicators of head authority and loyalty of the organization $(\mathrm{r}=0,62 ; \mathrm{p} \leq 0,05)$, satisfaction with the work schedule $(\mathrm{r}=0.47 ; \mathrm{p} \leq 0.05)$, labour renumeration $(\mathrm{r}=0.43 ; \mathrm{p} \leq 0.05)$ and job stability $(\mathrm{r}=0.53 ; \mathrm{p} \leq 0.05)$. Decision-making is also correlated with the efficiency of organising, management and supervision $(r=0.74 ; p \leq 0.01)$. One can make the conclusion that the efficiency of organizing, management and supervision interact with communication level $(\mathrm{r}=0.91 ; \mathrm{p} \leq 0.01)$ at the organization and job stability $(\mathrm{r}=0.77 ; \mathrm{p} \leq 0.01)$. As for the other indicators, we can observe the tendency to the interrelation, in particular, with loyalty at the organization $(\mathrm{r}=0.44 ; \mathrm{p} \leq 0.05)$. Such a strong interrelation of the efficiency of organizing, management, supervision and communication can be explained by the fact that the better the work, planning and informing are organized and the more interaction is observed at the enterprise, the more effective is the exchange of information between heads and top management team and subordinates. On the features of communication between the heads may depend the manifestation of loyalty of organization that is top management team to the lower managers $(\mathrm{r}=0.5 ; \mathrm{p} \leq 0.05)$, satisfaction with labour renumeration $(\mathrm{r}=0.4 ; \mathrm{p} \leq 0.05)$ and job satisfaction $(\mathrm{r}=0.56 ; \mathrm{p} \leq 0.05)$. It was revealed the interrelation of loyalty of the organization and acceptance of values $(\mathrm{r}=0.42 ; \mathrm{p} \leq 0.05)$, satisfaction with labour renumeration $(\mathrm{r}=0,52 ; \mathrm{p} \leq 0,05)$ and work schedule $(\mathrm{r}=0.43 ; \mathrm{p} \leq 0.05)$. We assume that the level of satisfaction with labour renumeration is due to the satisfaction with working conditions $(r=0.52 ; \mathrm{p} \leq 0.05)$ and work schedule $(\mathrm{r}=0.64 ; \mathrm{p} \leq 0.05)$.

\section{Conclusions}

One can observe an obvious tendency that the indicators of satisfaction with the work schedule, labour renumeration and stability of job are affected by the organizational climate factors. They include relations with colleagues, attitude to work, opportunities and desire for professional development, authority of the direct supervisor and head's decision-making. It is obvious that under the condition of the mutual understanding between employees, their cohesion and the authority of the head, the belief in the appropriate- 
ness of his decisions, the managers we are investigating, also evaluated in a more positive way the other factors of the organizational climate, namely, the general working conditions, including stability of work, satisfaction with the schedule and labour renumeration. The formation of favourable climate at the enterprise is a significant tool using which the head could improve the social and socio-economic efficiency of the organization staff. We can consider the degree of positive impact of management on the organizational climate as a way to improve the results of the team activity.

\section{References:}

1. Ahmetshin E.M., Pavljuk A.V., Gasanov E.L., Sverdlikova E.A., Kadirov M.A. (2018). Institucional'nye mehanizmy realizacii predprinimatel'skogo potenciala naselenija regiona. Zhurnal prikladnyh jekonomicheskih nauk, no. $13(7)$, s. 2052-2075.

2. Ahmetshin E.M., Vasil'ev V.L., Mironov D.S., Zacarinaja E.I., Romanova M.V., Jumashev A.V. (2018). Sistema vnutrennego kontrolja v upravlenii predprijatiem: matricy analiza i vzaimodejstvija. Evropejskij zhurnal issledovanij, no. 21(2), s. 728-740.

3. Kokorev A.S. Cifrovaja jekonomika: izmenenija cennostej i rukovodstva v upravlenii biznesom. Moskovskij jekonomicheskij zhurnal, 2019. № 1, c. 28.

4. Lishhinskaja E.A., Kmit M.I. (2014). Social'no-psihologicheskij klimaticheskij process upravlenija organizaciej. Nauchnyj zhurnal "Rynok truda i zanjatost", no. 4, s. 26-30.

5. Nejmer Ju.L. (1990). Social'no-psihologicheskij klimat kollektivnogo predprinimatel'stva. M.: Sociologicheskie issledovanija, s. 81-88.

6. Roshhin S.K. (1979). Social'no-psihologicheskij klimat komandy: teorija i metodika obuchenija. M.: Nauka, s. 103-116.

7. Chiker V.A. (2004). Psihologicheskij diagnoz organizacii i personala. $\mathrm{SPb} .:$ Rech', $176 \mathrm{~s}$.

8. Glisson, Charles; James, Lawrence R. (2002). The cross-level effects of culture and climate in human service teams. Journal of Organizational Behavior. 23(6), p. 767-794.

9. Freeman, R. Edward; Moutchnik, Alexander (2013). Stakeholder management and CSR: questions and answers. Umwelt Wirtschafts Forum. 21(1): 5-9. doi:10.1007/s00550-013-0266-3

10. Harris, L., Ogbonna, E. (2011). Antecedents and Consequences of Management-Espoused Organizational Cultural Control. Journal of Business Research. 64(5), p. 437-445. http://dx.doi.org/10.1016/j.jbusres.2010.03.002

11. Heath, Joseph (2006). "Business ethics without stakeholders". Business Ethics Quarterly. 16(3): 533-557.

12. Howell, A., Kirk-Brown, A., Cooper, B.K. (2012). Does Congruence Between Espoused and Enacted Organizational Values Predict Affective 
Commitment in Australian Organizations? The International Journal of Human Resource Management. 23(4), p. 731-747. http://dx.doi.org/10.1080/09585192.2 011.561251

13. Knights, D., Willmott, H. (1987). Organizational Culture as Management Strategy: A Critique and Illustration from the Financial Services Industry, Int Studies of Mgt \& Org. 17(3), p. 40-63. https://doi.org/10.1080/00208825.1987.1 1656461

14. Sathe, V. (1985). Culture and Related Corporate Realities. Homewood: Richard D. Irvin, Inc., 385 p.

15. Schein, E.H. (2010). Organizational Culture and Leadership. San Francisco: Jossey Bass. 